\title{
A interação entre o tratamento instrucional e a prontidão de desenvolvimento de aprendizes no processo de aquisição dos clíticos de terceira pessoa do espanhol ${ }^{1}$
}

\section{The interaction between the instructional treatment and the student development readiness in the process of acquisition of the clitics of third persons of Spanish}

Eduardo de Oliveira Dutra*

\begin{abstract}
RESUMO: Neste estudo, analisamos e discutimos a interação entre a prontidão de desenvolvimento de estudantes com mais e menos tempo de estudo e a intervenção instrucional destinada ao ensino dos clíticos de terceira pessoa do espanhol por universitários brasileiros. Os dados foram submetidos ao software International Business Machine Statistical Package for Social Studies (SPSS). Fizeram parte deste estudo 10 participantes de uma universidade pública. Os resultados, de modo geral, sugeriram evidências contrárias à Hipótese da Ensinabilidade.
\end{abstract}

PALAVRAS-CHAVE: Clíticos de terceira pessoa. Instrução com foco na forma. Espanhol.

\begin{abstract}
In this study, we analyzed and discussed the interaction between the readiness to develop students with more and less time of study and the instructional intervention destined to the teaching of the clitics of third persons of Spanish by Brazilian university students. Data were submitted to the International Business Machine Statistical Package for Social Studies software (SPSS). This study included 10 participants from a public university. The results suggested evidence contrary to the Teachability Hypothesis.
\end{abstract}

KEYWORDS: Clitics of third person. Instruction with a focus on form. Spanish.

\section{Introdução}

Estudos referentes à Instrução com Foco na Forma (doravante IFF) têm se ocupado de verificar a interação entre os tipos de instrução (explícita e implícita) e

\footnotetext{
${ }^{1}$ Este estudo é recorte da tese intitulada Os efeitos da instrução com foco na forma na aprendizagem dos clíticos de $3^{a}$ pessoa do espanhol por universitários brasileiros, que se desenvolveu, parcialmente, na Universidad de Salamanca (USAL), por meio do apoio do programa de Doutorado Sanduíche no Exterior (PDSE) da Coordenação de Aperfeiçoamento de Pessoal de Nível Superior (CAPES).

* Doutor em Linguística Aplicada (UNISINOS). Professor da Universidade Federal do Pampa (UNIPAMPA).
} 
uma série de fatores, no âmbito de aquisição ${ }^{2}$ de segunda língua (doravante ASL), tais como: (i) grau de complexidade das formas-alvo, (ii) constituição de conhecimento linguístico, (iii) instrução baseada na compreensão e na produção, (iv) prontidão de desenvolvimento, (v) redução de transferência, (vi) efeito e durabilidade, entre outros. No contexto brasileiro, é possível afirmarmos que ainda são poucos os estudos sobre a IFF que abrangem certos eixos temáticos (de (i) a (v)).

Neste estudo, escolhemos (i) e (iv), de modo integrado, em função da escassez de pesquisas, no país, que averiguam a interação entre a intervenção instrucional e a prontidão de desenvolvimento dos estudantes na aprendizagem de estruturas simples e de estruturas complexas do espanhol como língua estrangeira ${ }^{3}$ (doravante LE). Acrescentamos, a isso, o fato da seleção dos clíticos acusativos (Lo veo) e dos clíticos dativos em coocorrência com os clíticos acusativos de terceira pessoa (Se las vendemos), como objeto linguístico de instrução da presente pesquisa, de caráter intervencionista, ter sucedido pautada na literatura da ASL (GONZÁLEZ, 1994; VILLALBA, 1995; CRUZ, 2001, entre outros).

Para fins de organização do artigo, na sequência, apresentamos a fundamentação teórica, a qual é seguida da metodologia e da análise e discussão dos resultados. Por último, trazemos as considerações finais.

\section{Pressupostos teóricos}

\subsection{A instrução com foco na forma}

Spada (1997, p. 73) define instrução focada na forma (IFF) como "qualquer esforço pedagógico que é usado para chamar implícita ou explicitamente a atenção do

\footnotetext{
${ }^{2}$ Neste estudo, o conceito de aquisição será empregado como sinônimo de aprendizagem.

${ }^{3}$ Neste trabalho, a expressão língua estrangeira será empregada como sinônima de segunda língua (doravante L2).
} 
aprendiz para a forma da língua. Isso pode incluir o ensino da língua por meio de regras gramaticais e/ou reações para erros do aprendiz (feedback corretivo) ${ }^{4 \prime \prime}$.

O conceito a respeito de IFF, de Spada (1997), contempla tipos de instrução e estratégias pedagógicas destinadas ao direcionamento dos aprendizes para a forma, tais como: ensino de regras e feedback corretivo. Cabe destacarmos que forma não é sinônimo de gramática, uma vez que pode abranger aspectos pragmáticos, gramaticais, lexicais e fonológicos referentes à linguagem (ELLIS, 2001).

Por um lado, Norris e Ortega (2000) classificaram os estudos de sua metaanálise como pertencentes à instrução explícita se a explicação da regra compreendia parte da instrução ou se os alunos fossem diretamente convidados a prestar atenção a traços específicos e tentassem chegar a generalizações metalinguísticas por conta própria. Em comparação, se não houvesse nem a apresentação da regra, nem instruções destinadas ao direcionamento de atenção dos aprendizes a determinadas formas, esses procedimentos faziam parte de tratamento implícito.

Por outro lado, Spada (2010), a partir da análise de estudos a respeito de IFF, explicou que a instrução explícita remetia à situação na qual professores forneceram instruções e feedback corretivo, o que incluía o uso de metalinguagem e sinais claros para os alunos de que havia uma maneira certa e errada de dizer / escrever alguma coisa. Em contraste, em outros estudos, a IFF que foi fornecida, por meio de exposição dos aprendizes a alta frequência a um determinado traço linguístico, mas sem chamar a sua atenção para esse aspecto linguístico, de forma explícita ou através de recursos tipográficos, com ausência de instrução explícita ou feedback corretivo (SPADA, 2010), era enquadrada como de natureza implícita.

\footnotetext{
${ }^{4}$ Tradução nossa de: any pedagogical effort which is used implicitly or explicitly to call attention to the way the language learner. This may include direct teaching of language through grammar rules and / or reactions to the learner's errors.
} 
A partir do exposto, podemos afirmar que a intervenção explícita pode envolver explicações do funcionamento de regra, metalinguagem, feedback corretivo ou didática indutiva, enquanto que o tratamento implícito não requer nenhum desses tipos de estratégia pedagógica, mas sim exposição à forma-meta, em grande quantidade, e a utilização de recursos como negrito, itálico, aumento de fonte, entre outros recursos, a fim de despertar a atenção dos aprendizes para uma forma particular do insumo instrucional.

A instrução pode ser baseada na compreensão ou na produção. Devido ao fato de privilegiamos as tarefas de produção, durante a intervenção instrucional, no presente estudo, centramos nesse último tipo de instrução, que pretende promover a produção adequada das formas-meta. Em função disso, o uso de feedback corretivo é dirigido a qualquer erro que o aprendiz cometa nas tarefas de produção (SHINTANI; LI; ELLIS, 2013).

A produção linguística (SWAIN, 1995, 1998 e 2005) pode desencadear a percepção do novo traço, de problemas linguísticos e da diferença existente entre a sua representação na língua do aprendiz e o insumo na língua-alvo (Hipótese da Percepção da Lacuna ${ }^{5}$ ). Além disso, a produção dos estudantes na aprendizagem de uma L2 também pode estar relacionada à formulação e à comprovação de hipóteses. Por conseguinte, a produção linguística dos aprendizes pode ser um meio pelo qual os aprendizes testam hipóteses sobre como funcionam novas formas linguísticas na língua-alvo. Swain (2005) explica que o processo em que os aprendizes modificam sua produção linguística em reposta ao feedback faz parte da aprendizagem. Contudo, segundo essa pesquisadora, não se tem demonstrado que a produção modificada (reprocessada) prediz aprendizagem.

No presente estudo, para fins interpretativos dos dados, compreendemos efeito instrucional como o aumento da frequência das formas-alvo, em curto prazo, ao passo

\footnotetext{
${ }^{5}$ Noticing the Gap Hypothesis.
} 
que a durabilidade corresponde à estabilidade da frequência alcançada, no pós-teste imediato, no pós-teste postergado (em médio prazo). Já o termo avanço remete ao aumento contínuo das formas-meta nas fases I e II pós tratamento instrucional.

\subsection{O grau de complexidade das formas linguísticas e a prontidão de desenvolvimento dos aprendizes ${ }^{6}$}

A análise da complexidade dos traços linguísticos é problemática, visto que não existe consenso entre os pesquisadores sobre como traços linguísticos simples e complexos são conceituados e caracterizados (SPADA; TOMITA, 2010). O grau de complexidade das formas linguísticas é definido a partir de três perspectivas: psicolinguística, linguística ou pedagógica. Por razão de delimitação, focaremos a primeira perspectiva. Nessa visão, dois critérios são utilizados para o estabelecimento da complexidade de traços linguísticos, a saber: aquisição precoce ou tardia da formaalvo e menor ou maior dificuldade de processamento.

Por conseguinte, por exemplo, traços adquiridos precocemente são caracterizados como formas simples, ao passo que, no sentido inverso, as formas linguísticas são identificadas como estruturas complexas. A fim de caracterizarmos as formas-alvo deste estudo, em termos de complexidade, e de discutirmos a interação entre a IFF e a sequência de desenvolvimento dos aprendizes, a seguir, discorreremos a respeito da Hipótese de Ensinabilidade (PIENEMANN, 1989) e retomaremos o estudo de Klee (1989).

Ao longo dos anos, houve uma série de estudos (MEISEL; CLAHSEN; PIENEMANN, 1981; PIENEMANN, 1987; PIENEMAN; JOHNSTON; BRINDLEY, 1988; PIENEMANN, 1989) sobre as sequências de aquisição de traços linguísticos na ASL e a respeito da interação entre essas etapas de desenvolvimento e o ensino formal.

\footnotetext{
${ }^{6}$ Houve a publicação parcial desta seção na obra Retratos de Linguagem.

7 Tradução nossa de Teachability Hypotheses.
} 
O progresso dos aprendizes, ao longo dos estágios de desenvolvimento, é dependente de sua capacidade de processamento psicolinguístico (MEISEL; CLAFHSEN; PIENEMANN, 1981). Em outras palavras, o processamento de um traço linguístico de um estágio específico está relacionado ao fato de o aprendiz ter sido capaz de processar o(s) aspecto(s) linguísticos do estágio anterior. Portanto, uma etapa serve de prérequisito para outra.

A prontidão do desenvolvimento dos aprendizes refere-se às restrições de processamento que funcionam como pré-requisitos para a aquisição de formas específicas (BARDOVI-HARLIG; COMAJOAN, 2008). Por conseguinte, do ponto de vista do desenvolvimento, o aprendiz está pronto para adquirir um traço específico se os pré-requisitos para o estágio seguinte tiverem sido cumpridos. A título de exemplo, a operação do processamento caracterizada por X+1 é também adquirida para o estágio $X+2$. De igual maneira, a operação integrante do estágio $X+2$ é necessária para o estágio X+3. (PIENEMANN, 1989). Portanto, cada estrutura adquirida mais tarde requer uma operação adicional. Em função disso, estruturas do estágio $X+3$ não podem ser processadas no estágio $X+1$, visto que os aprendizes não adquiriram ainda o prérequisito necessário para o processamento da operação em questão (PIENEMANN, 1989).

A fim de que a interação entre a IFF e a sequência de desenvolvimento produza impacto positivo, a partir da Hipótese da Ensinabilidade (PIENEMANN, 1985 e 1989), é necessário que a intervenção didática seja organizada de acordo com o nível de preparação psicolinguística dos estudantes. A instrução explícita é capaz de melhorar a aquisição da L2 em relação à velocidade de aquisição, à frequência na aplicação da regra e aos diferentes contextos em que a regra deve ser aplicada, desde que o aprendiz esteja no estágio de aquisição adequado (PIENEMANN, 1985).

Portanto, a intervenção instrucional resultará benéfica na ASL apenas se está em uma etapa além do estágio de desenvolvimento atual, ou seja, se o ensino direciona 
o aprendiz para o seu próximo nível de desenvolvimento. Sendo assim, o insumo instrucional $^{8}$ destinado a etapas inferiores ou superiores ao estágio de desenvolvimento atual dos aprendizes provavelmente será menos efetivo no avanço dos estudantes para o seu próximo nível de desenvolvimento.

O estudo de síntese narrativa realizado por Spada (1997) e a meta-análise de Spada e Tomita (2010) apontaram que os resultados das pesquisas a respeito da interação da intervenção pedagógica com o nível de desenvolvimento dos aprendizes têm sido mistos. De um lado, há pesquisas (PINENMANN, 1984, 1988 e 1989; MACKEY, 1995; MACKEY; PHILP, 1998) que corroboram a hipótese de que os aprendizes se beneficiam mais da instrução que é dirigida para o seu próximo estágio de desenvolvimento. De outro lado, existem investigações (DOUGHTY, 1991; SPADA; LIGHTBOWN, 1999), cujos resultados apresentaram evidências contrárias a essa hipótese. Em outras palavras, a IFF foi efetiva quando esteve dirigida a estágios além da etapa de desenvolvimento atual dos aprendizes.

Conforme afirmamos anteriormente, o tempo de aquisição de formas linguísticas varia. Existem estruturas que são adquiridas mais cedo do que outras, e, em consequência disso, aquelas formas linguísticas, pertencentes a estágios anteriores, são pré-requisitos para o processamento das estruturas linguísticas adquiridas mais tarde. Segundo o estudo de Klee (1989), no grupo dos pronomes de terceira pessoa, as formas le e lo foram adquiridas em primeiro lugar e sucedidas por les e los. Por último, foram adquiridas as formas la e las.

Ao partirmos dos critérios psicolinguísticos mencionados, para a caracterização das formas-alvo deste estudo como estruturas simples e complexas e dos resultados da investigação supracitada, três questões merecem ser elucidadas. Em primeiro lugar,

\footnotetext{
8 Há discussões referentes a algumas limitações a respeito da proposta de Pienenmann (1985). Lightbown (1998), dentre uma série de questões, aponta que a heterogeneidade das turmas é uma realidade que faria que o ensino centrado no desenvolvimento fosse difícil de organizar.
} 
nesta pesquisa, categorizamos as formas clíticas de terceira pessoa lo(s) e la(s) indistintamente como formas únicas, isto é, não as codificamos por separado. Em segundo lugar, não consideramos as formas $l e(s)$ no grupo das formas únicas. Por último, os resultados do estudo de Klee (1989) não fazem menção direta à aquisição das formas duplicadas.

Em função disso, não pudemos observar e descrever o padrão de aquisição das formas únicas de igual maneira que Klee (1989) e, tampouco, averiguarmos de que maneira essas formas interagem, separadamente, em função do caso, gênero e número com a intervenção pedagógica adotada neste estudo.

Contudo, a fim de mitigarmos as limitações apontadas, para a definição da complexidade das formas linguísticas sob exame, procedemos da seguinte maneira: analisamos e comparamos os dados obtidos, na fase anterior ao tratamento instrucional, a respeito das formas únicas e duplicadas, entre os aprendizes com menor e maior tempo de estudo do espanhol; partimos do pressuposto de que mais tempo de contato com a língua-alvo poderia implicar maior frequência de estruturas linguísticas adquiridas tardiamente (DOUGHTY, 1991).

De uma parte, no pré-teste, a partir da análise e da comparação dos dados linguísticos entre os aprendizes de dois níveis (tempos) de estudo, procedimento pautado no trabalho de Doughty (1991), observamos que estudantes mais experientes na aprendizagem do espanhol apresentaram maiores índices de ocorrência das formas únicas e duplicadas, com margem a favor da primeira categoria de formas clíticas de terceira pessoa, em comparação ao grupo menos experiente, no qual as formas únicas também foram as que obtiveram os maiores índices de frequência. De outra parte, no estudo de Klee (1989), os informantes do estudo (Carmen, Marta, Alberto e Eduardo) representaram estágios de aquisição de espanhol L2. Nesse sentido, Eduardo, o último informante, apresentou com mais frequência a forma $l a$, estrutura que integra o grupo 
de formas únicas adquiridas por último, em comparação ao informante 3, Alberto, que não a produziu.

A partir do exposto, é necessário tecermos algumas considerações. Parece que as formas únicas são adquiridas mais cedo do que as formas duplicadas, visto que, neste estudo, independentemente do tempo de estudo do espanhol, sua produtividade foi maior do que a frequência das formas duplicadas. Além disso, essas formas clíticas apresentaram, na fase anterior ao tratamento instrucional, maior índice de produtividade entre os aprendizes com maior tempo de estudo, evidência favorável ao pressuposto de que as formas linguísticas adquiridas mais tarde são mais frequentes entre os aprendizes mais experientes na aprendizagem de uma LE.

Se os aprendizes com mais tempo de contato formal com o espanhol apresentam maior número de pré-requisitos, para alcançar o seu estágio de desenvolvimento atual, em comparação aos estudantes menos experientes, supomos que aqueles aprendizes estão prontos, do ponto de vista do desenvolvimento, para a aquisição de estruturas tardias. Portanto, a partir do critério psicolinguístico de aquisição precoce ou tardia de uma estrutura linguística e das discussões realizadas até o momento, neste estudo, caracterizamos as formas únicas e duplicadas, respectivamente, como estruturas simples e complexas.

Em suma, o aprendiz está pronto, do ponto de vista do desenvolvimento, se as restrições impostas pelas etapas anteriores forem superadas. Quanto à interação entre a intervenção pedagógica e o estágio de desenvolvimento, segundo a Hipótese da Ensinabilidade, o direcionamento para o próximo estágio de desenvolvimento do aprendiz, que corresponde ao ajuste da intervenção pedagógica para o estágio linguístico seguinte, produz benefícios na ASL, tais como: velocidade de aquisição e frequência na aplicação da regra alvo. Contudo, existem evidências de que o tratamento instrucional dirigido a estágios mais avançados ocasiona benefícios na 
ASL. Por último, as formas únicas e duplicadas de terceira pessoa deste estudo são caracterizadas, respectivamente, como formas simples e complexas.

\section{Metodologia}

Integraram este estudo, de caráter quase-experimental, 10 estudantes do Curso de Letras Espanhol/Português e respectivas Literaturas de uma universidade pública, localizada no interior do Rio Grande do Sul. Esses estudantes cursavam o terceiro, quinto e sétimo semestres, dentre os quais, os do primeiro grupo fizeram parte da classe de alunos com menos tempo de estudo, ao passo que os restantes foram classificados como pertencentes ao conjunto de aprendizes com mais tempo de estudo. Para a aplicação da intervenção instrucional e coleta de dados, dois professores do referido curso participaram da investigação como colaboradores. Os objetivos que nortearam o presente estudo foram:

- Caracterizar os clíticos acusativos (formas únicas) e os clíticos dativos em coocorrência com os clíticos acusativos (formas duplicadas) de terceira pessoa do espanhol a partir do grau de complexidade.

- Examinar a interação entre o tratamento instrucional e a etapa de desenvolvimento dos aprendizes, através da análise da produtividade das formas simples e complexas do espanhol, nas fases I e II pós-tratamento, entre os aprendizes com menor e maior tempo de estudo.

- Abordar implicações (pedagógicas e teóricas) a respeito do ensino de estruturas simples e complexas segundo o nível de estudo dos aprendizes.

A hipótese correspondente ao segundo objetivo supracitado é a que segue: Os aprendizes mais experientes na aprendizagem do espanhol apresentarão, nas fases I e II pós-intervenção pedagógica, os maiores índices de acurácia das formas-alvo, do que os alunos com menos tempo de estudo (PIENEMANN, 1985, 1989). 
Os participantes foram selecionados a partir dos seguintes critérios: ser brasileiro; não ter ascendência hispânica; ter cursado, no mínimo, dois semestres das disciplinas de espanhol; participar de todas as etapas de coleta de dados. No que concerne ao intervalo entre a intervenção instrucional e as fases pós-instrucionais, é possível afirmarmos a existência de variação de três a quatro semanas (curto prazo) e nove e dez semanas (médio prazo).

O tratamento instrucional destinado ao ensino das formas simples e complexas abrangeu as seguintes estratégias pedagógicas: informações contrastadas entre o português brasileiro (doravante $\mathrm{PB}$ ) e o espanhol a respeito das formas-alvo, evidências negativas, didática dedutiva, tarefa de compreensão e tarefas de produções livres e controladas. Entretanto, cabe destacarmos que foi a instrução explícita a que predominou, durante a intervenção pedagógica, uma vez que as demais estratégias pedagógicas incluíram a retomada de questões relacionadas às formas clíticas de terceira pessoa via metalinguagem e descrição de seu funcionamento na língua-alvo.

Para a obtenção dos dados, os instrumentos consistiram em pré-teste, pós-teste imediato e pós-teste postergado, os quais abrangeram teste de julgamento de gramaticalidade cronometrado, teste de julgamento de gramaticalidade não cronometrado, teste de imitação oral, teste livre de descrição de sequência de imagens, teste controlado de descrição de sequência de imagens e teste de narrativa oral.

Para fins de análise estatística dos dados, utilizamos o software International Business Machine Statistical Package for Social Studies (SPSS), ${ }^{9}$ a partir do qual fizemos uso de frequência relativa, Teste de Qui-quadrado e Teste de ANOVA de medidas repetidas. A seguir, apresentamos a análise e discussão dos resultados.

\footnotetext{
${ }^{9}$ Uma análise mais apurada foi realizada por meio do teste da árvore CHAID que controla todas as variáveis do estudo, seleciona e organiza hierarquicamente, através de galhos, as variáveis que mais influenciam a aplicação da variável dependente. Contudo é válido destacar que, em função da natureza do teste referido, não será possível trazer apenas dados do presente estudo, produto de um recorte. Um estudo mais amplo, que inclui o teste de árvore CHAID, está em processo de organização.
} 


\section{Análise e discussão dos resultados}

Nossa hipótese de que o tratamento instrucional motivaria mais a produtividade das formas-alvo, em curto e em médio prazos, entre os aprendizes com maior tempo de estudo não foi confirmada.

No Quadro 1, a seguir, apresentamos a frequência das formas simples, durante as etapas de obtenção dos dados, entre os aprendizes com menos e mais tempo de estudo do Espanhol.

Quadro 1 - Produtividade das formas simples, nas etapas de coleta, entre os aprendizes com menos e mais tempo de estudo.

\begin{tabular}{|c|c|c|}
\hline Fatores & $\begin{array}{c}\text { Formas Simples menos } \\
\text { Tempo de Estudo do } \\
\text { Espanhol }\end{array}$ & $\begin{array}{c}\text { Formas Simples mais } \\
\text { Tempo de Estudo do } \\
\text { Espanhol }\end{array}$ \\
\hline $\begin{array}{c}\text { Pré-teste (PR) } \\
\text { Pós-teste imediato } \\
\text { (PI) }\end{array}$ & $143 / 513=28 \%$ & $186 / 337=55.2 \%$ \\
\hline $\begin{array}{c}\text { Pós-teste postergado } \\
\text { (PP) }\end{array}$ & $427 / 636=67.1 \%$ & $205 / 322=63.7 \%$ \\
\hline
\end{tabular}

Fonte: elaborado pelo autor.

Na leitura vertical do Quadro 1, observamos que as formas simples, nas fases I e II pós-tratamento instrucional, aumentaram a sua frequência entre os aprendizes com menor tempo de estudo. Por sua vez, no grupo de aprendizes com mais tempo de estudo, essas formas linguísticas aumentaram sua frequência unicamente na fase I pósintervenção pedagógica. Na fase II pós-tratamento instrucional, a frequência dessas formas foi reduzida. A fim de averiguarmos a produtividade das formas complexas, durante as etapas de coleta de dados, entre os aprendizes com menor e maior nível de estudo, apresentamos, a seguir, o Quadro 2. 
Quadro 2 - Produtividade das formas complexas nas etapas de coleta entre os aprendizes com menor e maior nível de estudo.

\begin{tabular}{|l|c|c|}
\hline \multicolumn{1}{|c|}{ Fatores } & $\begin{array}{c}\text { Formas complexas menos } \\
\text { Tempo de Estudo do } \\
\text { Espanhol }\end{array}$ & $\begin{array}{c}\text { Formas complexas mais } \\
\text { Tempo de Estudo do } \\
\text { Espanhol }\end{array}$ \\
\hline Pré-teste (PR) & $43 / 308=14 \%$ & $67 / 194=34.5 \%$ \\
\hline $\begin{array}{l}\text { Pós-teste } \\
\text { imediato (PI) }\end{array}$ & $243 / 393=61.8 \%$ & $154 / 281=54.8 \%$ \\
\hline $\begin{array}{l}\text { Pós-teste } \\
\text { postergado } \\
\text { (PP) }\end{array}$ & $240 / 290=82.8 \%$ & $164 / 225=73 \%$ \\
\hline
\end{tabular}

Fonte: elaborada pelo autor.

No Quadro 2, constatamos que as formas complexas avançaram, ao longo das etapas de obtenção dos dados, nos dois níveis de estudo. Para fins de análise estatística mais apurada, recorremos ao teste de $\chi^{2}$ e ao teste de ANOVA de medidas repetidas. O valor do primeiro teste $\left(\right.$ de $\chi^{2}=93.671$; valor $\left.\mathrm{p}=0.00\right)$ e os índices do teste de ANOVA de medidas repetidas, com os valores $\mathrm{p}=0.10$ e $\mathrm{p}=0.08$, respectivamente, referentes às formas simples e complexas, revelaram-se significativos estatisticamente a nível de significância de 10\%. Essa diferença estatística entre as formas simples e complexas, em curto e em médio prazos, por nível de estudo, possivelmente ocorreu devido à amostra reduzida, visto que, na amostra geral, produto da soma da produtividade de ambas as formas clíticas de terceira pessoa, o valor de $\mathrm{p}$ foi $<0.05$. Apesar das diferenças de nível de significância, os testes se mostraram relevantes estatisticamente. Isso significa que há um efeito da interação entre o tratamento instrucional e a produtividade das formas simples e complexas entre os alunos participantes com menos e mais tempo de estudo do espanhol.

Para fins elucidativos dos resultados anteriores, obtidos por separado, apresentamos, na sequência, o Gráfico 1, em que comparamos a produtividade das formas simples e complexas, nas fases I e II pós-tratamento instrucional, entre os aprendizes com menos e mais tempo de aprendizagem formal do espanhol. A legenda que utilizamos no Gráfico abaixo é a seguinte: 1= formas simples entre aprendizes com 
menos tempo de estudo; 2=formas simples entre aprendizes com mais tempo de estudo; 3=formas complexas entre aprendizes com menos tempo de estudo e $4=$ formas complexas entre aprendizes com mais tempo de estudo.

Gráfico 1 - Produtividade das formas simples e complexas nas etapas de coleta por aprendizes com menos e mais tempo de estudo do espanhol.

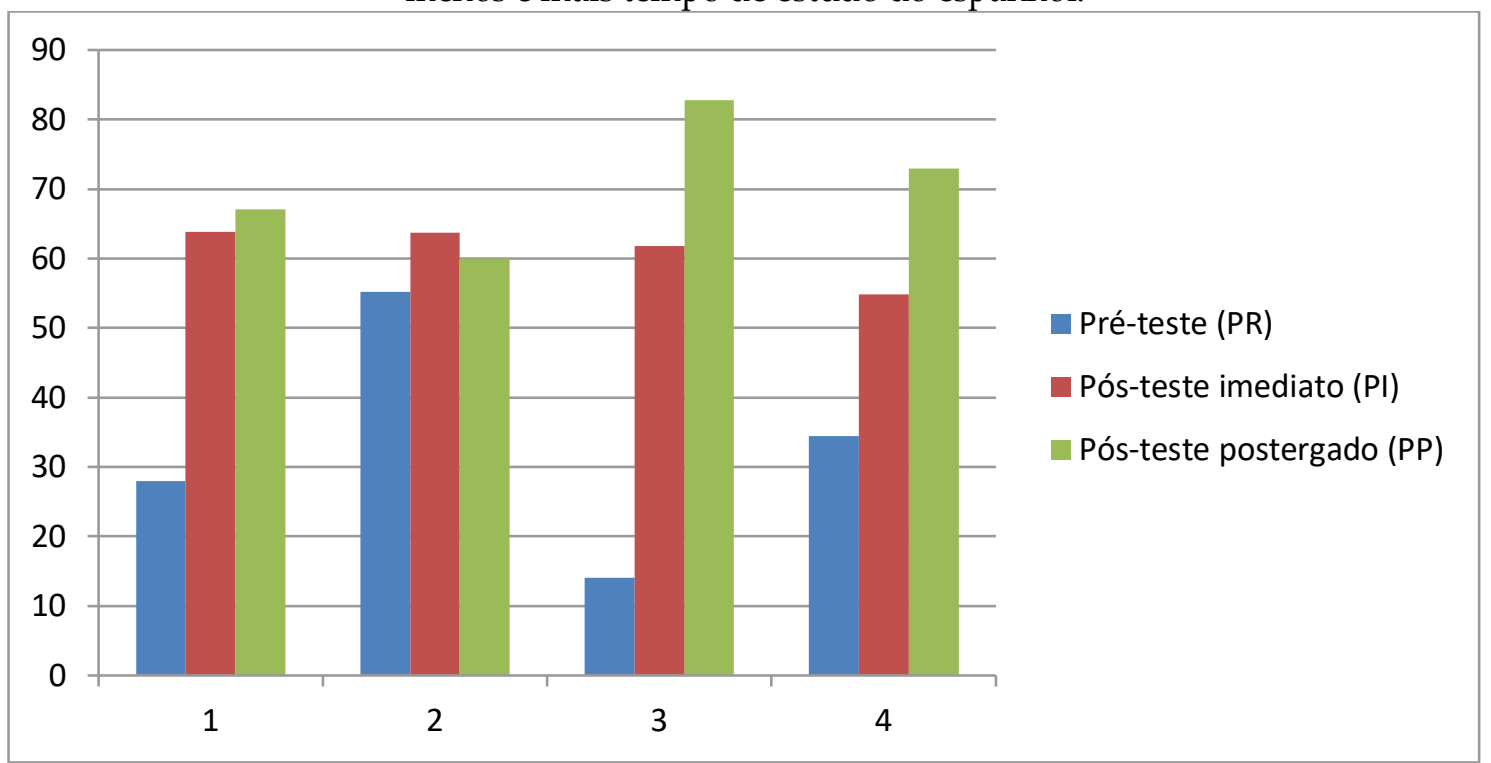

Fonte: elaborado pelo autor.

No Gráfico 1, apesar dos percentuais de frequência das formas simples, em curto prazo, nos dois grupos por tempo de estudo, terem sido praticamente idênticos, é possível observarmos, no Gráfico 1, que as formas simples foram mais recorrentes, na fase anterior à intervenção instrucional, entre os aprendizes com maior tempo de estudo.Se considerarmos a maior frequência das formas simples, no PR, entre os estudantes com mais tempo de estudo na aprendizagem do espanhol, a fim de analisarmos a diferença de aplicação dessas formas linguísticas, nos dois grupos por tempo de estudo, entre a fase anterior à intervenção instrucional e a fase I pósintervenção pedagógica, é possível afirmarmos que o aumento das formas-alvo, em curto prazo, foi maior entre os aprendizes com menos tempo de estudo.

Além disso, podemos constatar que as formas simples avançaram apenas no grupo dos alunos participantes com menor tempo de estudo, uma vez que, entre os 
aprendizes com maior tempo de estudo, na fase II pós-instrucional, houve estabilidade da frequência das formas-alvo obtida em curto prazo. Com a intenção de ilustrarmos a produtividade das formas simples, apresentamos os seguintes exemplos:

(1) Sí, lo vendió.

(informante 1, com menos tempo de estudo formal do espanhol, fase I póstratamento)

(2) Sí, los mando siempre.

(informante 4, com menos tempo de estudo formal do espanhol, fase I póstratamento)

(3) Pedro viu la gorra, la usó, la compró, en casa la usó nuevamente, la planchó, la guardó, después la agarró.

(informante 8, com mais tempo de estudo formal do espanhol, fase II póstratamento)

(4) Antonio vio las bermudas en la vidriera, y decidió usarlas, las usó, vio que estaban arrugadas y por eso las planchó y las guardó en el guardarropa.

(informante 9, com mais tempo de estudo formal do espanhol, fase II póstratamento)

Conforme podemos observar no Gráfico 1, em comparação, as formas complexas, ainda que tenham avançado, em curto e em médio prazos, independentemente do tempo de estudo, foram mais produtivas, ao longo das fases pós-intervenção pedagógica, também no grupo dos aprendizes com menos tempo de estudo do espanhol. A fim de evidenciarmos a frequência das formas complexas, indicamos os exemplos ${ }^{10}$ a seguir:

\footnotetext{
${ }^{10}$ Exemplos oriundos de respostas referentes a perguntas, como em ¿Comes frutas rojas? e no caso de ¿Planchó las ropas a las señoras?.
} 
(5) No, no se lo regalaron.

(informante 10, com mais tempo de estudo formal do espanhol, fase I póstratamento instrucional)

(6) Sí, se los compro.

(informante 8, com mais tempo de estudo formal do espanhol, fase I póstratamento instrucional)

(7) Sí, se la conté.

informante 9, com mais tempo de estudo formal do espanhol, fase II póstratamento instrucional)

(8) No, no se las hacía

(informante 8, com mais tempo de estudo formal do espanhol, fase II póstratamento instrucional)

Se considerarmos a existência de uma ordem na aquisição de traços linguísticos da língua-alvo (MEISEL; CLAFHSEN; PIENEMANN, 1981), há formas linguísticas que são adquiridas mais precocemente do que outras estruturas linguísticas. Há indícios de que, na aprendizagem de espanhol como LE, a aquisição das formas duplicadas ocorre mais tarde em comparação às formas únicas. Em virtude disso, com base em critérios psicolinguísticos, caracterizarmos as formas únicas e duplicadas, respectivamente, como formas simples e complexas, conforme já apontamos anteriormente.

Estudos a respeito dos efeitos do tipo de instrução atrelados à complexidade das formas-alvo têm apontado resultados mistos. Segundo a meta-análise de Spada e Tomita (2010), a eficácia da instrução explícita foi efetiva independentemente do grau de complexidade do traço linguístico. Isso corrobora as evidências do estudo de Housen, Pierrard e Daele (2005) a respeito da interação da instrução explícita com sentenças de negação (formas simples) e voz passiva (formas complexas) por aprendizes de francês L2, que revelou a eficácia da intervenção pedagógica adotada no ensino de traços simples e complexos. 
Os objetos linguísticos de instrução deste estudo foram produtivos durante as etapas de coleta de dados. A variação existente quanto à produtividade das formasalvo indicou aumento e/ou estabilidade dos seus índices de frequência nas fases I e II pós-tratamento instrucional, conforme observamos nos Quadros 1 e 2. Por conseguinte, as formas clíticas de terceira pessoa foram sensíveis ao tratamento instrucional. A intervenção pedagógica administrada parece ter beneficiado, nas fases pós-intervenção pedagógica, tanto a produtividade das formas simples quanto dos traços complexos (HOUSE, PIERRARD; DAELE, 2005; SPADA; TOMITA, 2010), com margem de vantagem favorável a essas formas linguísticas, respectivamente, em curto e em médio prazos, entre os aprendizes com menos tempo de estudo.

A partir da Hipótese da Ensinabilidade (PIENEMANN, 1985 e 1989), o tratamento instrucional deve estar direcionado para a próxima etapa de desenvolvimento dos aprendizes. Do ponto de vista pedagógico, é necessário que o material didático esteja em um nível além da sua etapa de desenvolvimento atual. Os estudantes com mais tempo de estudo, a partir de uma visão psicolinguística, estão mais preparados para a aquisição de formas complexas, em comparação aos aprendizes com menor nível de estudo que apresentam prontidão de desenvolvimento compatível para a aquisição de estruturas simples (adquiridas mais cedo).

Durante a aplicação das estratégias pedagógicas, que constituíram a intervenção instrucional, os professores colaboradores propiciaram condições para que os aprendizes percebessem estruturas adequadas à sua prontidão de desenvolvimento, nos casos de instrução destinada às formas simples e complexas, respectivamente, a aprendizes com menor e maior tempo de estudo.

Entretanto, cabe assinalarmos que, além das estratégias pedagógicas terem sido direcionadas a formas linguísticas adequadas à etapa de desenvolvimento atual dos aprendizes, a intervenção instrucional esteve aquém e além da sua prontidão de desenvolvimento, uma vez que aprendizes com mais tempo de estudo foram expostos 
a insumo instrucional direcionado a formas simples. Por sua vez, alunos participantes com menor nível de estudo, por exemplo, receberam instrução explícita destinada a formas complexas. Portanto, ora o tratamento instrucional se ajustou à prontidão de desenvolvimentos dos aprendizes - conforme a Hipótese da Ensinabilidade (PIENEMANN, 1985 e 1989) -, ora esteve em descompasso com a sua etapa de desenvolvimento.

A partir dos dados obtidos, é possível observarmos que o tratamento instrucional produziu efeitos benéficos, no que se refere à aprendizagem das formasalvo, entre os estudantes com maior e menor de tempo de estudo, com margem de vantagem a favor desse último grupo. Além disso, cabe destacarmos que foram as formas complexas as que apresentaram o maior índice de frequência entre os aprendizes menos experientes na aprendizagem do espanhol. Logo, há evidências favoráveis à exposição dos aprendizes a insumo instrucional além de sua prontidão de desenvolvimento.

\section{Considerações finais}

Esta investigação nos possibilitou examinar a interação entre o tratamento instrucional e a prontidão de desenvolvimento de grupos de aprendizes com menor e maior tempo de estudo durante o processo de aprendizagem de formas simples e formas complexas, em curto e em médio prazos. Para nortearmos esta pesquisa, partimos dos objetivos e da hipótese apontados anteriormente, os quais retomamos, na sequência, a fim de tecermos as considerações finais do presente estudo.

O nosso primeiro objetivo estava relacionado à caracterização dos clíticos acusativos (formas únicas) e dos clíticos dativos em coocorrência com os clíticos acusativos (formas duplicadas) de terceira pessoa do espanhol a partir do seu grau de complexidade. No que tange a essa questão, a análise dos dados, oriundos do pré-teste 
entre estudantes com níveis distintos de tempo de estudo, indicou maior aplicação das formas duplicadas entre os estudantes com mais tempo de estudo.

Se partimos do pressuposto de que estruturas tardias (critério psicolinguístico) são mais frequentes entre estudantes mais experientes na aprendizagem formal de uma LE, a tendência apontada anteriormente, nos permite classificar os clíticos acusativos e os clíticos dativos em coocorrência com os clíticos acusativos de terceira pessoa do espanhol, respectivamente, como formas simples e formas complexas.

O segundo objetivo do presente estudo remetia ao exame da interação entre a IFF e a etapa de desenvolvimento dos aprendizes. A esse respeito, a hipótese de que os aprendizes com maior tempo de estudo apresentariam maiores índices de produtividade das formas-alvo não foi confirmada. Os dados sugeriram, com base na análise do grupo de fatores formas simples e complexas entre aprendizes com menor e maior tempo de estudo, que as formas simples avançaram entre os aprendizes com menor nível de estudo, ao passo que as formas complexas avançaram em ambos os grupos, com margem de vantagem a favor dos aprendizes com menor tempo de estudo, principalmente, em curto prazo.

O terceiro objetivo remetia à abordagem de implicações pedagógicas e teóricas a respeito do ensino de estruturas simples e complexas segundo o nível de estudo dos aprendizes. No que concerne a esse aspecto, o fornecimento instrucional, além da prontidão de desenvolvimento dos aprendizes, parece ter favorecido o processo de aquisição de estruturas complexas entre aprendizes que não estariam preparados, do ponto de vista psicolinguístico, para a sua aquisição e, em decorrência, trouxe evidências contrárias à Hipótese da Ensinabilidade (PIENEMANN, 1985 e 1989). Logo, parece haver evidências favoráveis à exposição de estudantes a tratamentos instrucionais que ultrapassem a sua prontidão de desenvolvimento.

Quanto às limitações desta investigação, apontamos o fato de termos codificado as formas acusativas de terceira pessoa de modo indiscriminado, isto é, sem levarmos 
em consideração separadamente aspectos como gênero, número e pessoa. Em função disso, sugerimos, para estudos futuros, tais procedimentos, os quais podem ser acompanhados de uma reclassificação do grau de complexidade das formas-alvo sob análise.

\section{Referências Bibliográficas}

BARDOVI-HARLIG, K.; COMAJOAN, L. Order of Acquisition and Developmental Readiness. In: SPOLSKY, B.; HULT, F. (org.). The Handbook of Educational Linguistics. Australia: M. Blackwell Publishing, 2008. DOI https://doi.org/10.1002/9780470694138.ch27

CRUZ, M. L. O. B. Estágios de interlíngua: estudo longitudinal centrado na oralidade de sujeitos brasileiros aprendizes de espanhol. 2001. 316 f. Tese (Doutorado em Estudos da Linguagem) - Universidade Estadual de Campinas (UNICAMP), Campinas, 2001.

DOUGHTHY, C; WILLIAMS, J. Focus on form: theory, research, and practice. (ed). Focus on form in classroom second language acquisition. Cambridge: CUP, 1998.

DOUGHTY, C. Second language instruction does make a difference: Evidence from an empirical study of ESL relativization. Studies in Second Language Acquisition, 13 (2), 431-469.

ELLIS, R. Introduction: Investigating form-focused instruction. Language Learning, S1: Supplement 1, p. 1-46, 2001. DOI https://doi.org/10.1111/j.1467-1770.2001.tb00013.x

ELLIS, R.; LOEWEN, S.; ELDER, C.; ERLAM, R.; PHILP, J.; HAYO, R. Implicit and Explicit Knowledge in Second Language Learning, Testing and Teaching. Bristol: Short Run Press, 2009.

GONZÁLEZ, N. T. M. Cadê o pronome? O gato comeu. 1994. 451 f. Tese (Doutorado em Letras), Universidade de São Paulo (USP), São Paulo, 1994.

KONSTANTOPOULOS, S.; HEDGES, L. Meta-Analysis. In: KAPLAN, D. (ed.). Handbook of Quantitative Methodology for the Social Sciences. New York: Sage, p. 281-297, 2004. 
KLEE, C. A. The acquisition of clitic pronouns in the Spanish interlanguage of Quechua speakers: A contrastive case study. Hispania, v. 72, p. 402-408, 1989. DOI https://doi.org/10.2307/343164

LYSTER, R.; RANTA, L. Corrective feedback and learner uptake negotiation of form in communicative classroom. Studies in second Language Acquisition (SSLA), v.9, p. 37-66, 1997.

MEISEL, J.; CLAHSEN, H.; PIENEMANN, M. On determining developmental stages in natural second language acquisition. Studies in Second Language Acquisition, v. 3 (2) 109-35, 1981. DOI https://doi.org/10.1017/S0272263100004137

NORRIS, J.; ORTEGA, L. Effectiveness of L2 instruction: A research synthesis and quantitative meta-analysis. Language Learning, 50, 417-528, 2000. DOI https://doi.org/10.1111/0023-8333.00136

PIENEMANN, M. Psychological constraints on the teachability of languages. Studies in Second Language Acquisition, 6 (2), 186-214, 2008. DOI https://doi.org/10.1017/S0272263100005015

PIENEMANN, M. Learnability and syllabus construction. In: HYLTENSTAM, K.; PIENEMANN, M. (ed.). Modeling and assessing second language acquisition. Clevedon, Avon: Mutilingual Matters, 1985. p. 23-75.

PIENEMANN, M. Is language teachable? Applied Linguistics, 10 (1) 52-79, 1989. DOI https://doi.org/10.1093/applin/10.1.52

PIENEMANN, M. Determining the influence of instruction on L2 speech processing. Australian Review of Applied Linguistics, 10 (2), 83-113, 1983. DOI https://doi.org/10.1075/aral.10.2.07pie

PIENEMANN, M.; JOHNSTON, M.; BRINDLEY, G. Constructing an acquisitionbased procedure for second language assessment. Studies in Second Language

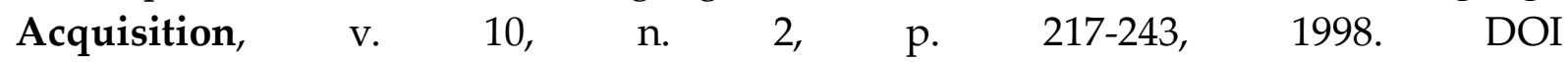
https://doi.org/10.1017/S0272263100007324

SHINTANI, N.; LI, S.; ELLIS, R. Comprehension-Based Versus Production-Based Grammar Instruction: A Meta-Analysis of Comparative Studies. Language Learning, v. 63, n. 2, 2013 p. 296-329. DOI https://doi.org/10.1111/lang.12001 
SWAIN, M. Three functions of output in second language learning. In: COOK, G.; SEIDLHOFER, B. (Orgs.). Principles and practice in applied linguistics: Studies in honour of H. G. Widdowson. Oxford, UK: Oxford University Press, 1995, p. 125-144.

SWAIN, M. Atención a la forma a través de la reflexión consciente. In: DOUGHTY, C.; WILLIAMS, J. (org.). Atención a la forma en la adquisición de segundas lenguas en el aula. Traducción y edición española Editorial Edinumen, 1998.

SWAIN, M. The output hypothesis: Theory and research. In: HINKEL, E. (org.). Handbook on research in second language teaching and learning. New Jersey: Lawrence Erlbaum Associates, 2005, p. 471-483.

SWAIN, M.; LAPKIN, S. Problems in output and cognitive processes they generate: a step toward second language learning. Applied Linguistics, v. 16, p. 371-391, 1994. DOI https://doi.org/10.1093/applin/16.3.371

SPADA, N. Form-focused instruction and second language acquisition: A review of classroom and laboratory research. Language Teaching. 30, 73-87. 1997. DOI https://doi.org/10.1017/S0261444800012799

SPADA, N. Beyond form-focused instruction: Reflections on past, present and future research. Language Teaching, 44, 225-236, 2010. DOI https://doi.org/10.1017/S0261444810000224

SPADA, N. Form-focused instruction: isolated or integrated? TESOL Quartely, 42 (2), 181-207. 2008. DOI https://doi.org/10.1002/j.1545-7249.2008.tb00115.x

SPADA, N.; TOMITA, Y. Interactions between type of instruction and type of language feature: A meta-analysis. Language Learning, 60(2), p. 1-46, 2010. DOI https://doi.org/10.1111/j.1467-9922.2010.00562.x

VILLALBA, T. K. B. A transferência na aquisição da anáfora pronominal em espanhol por universitários brasileiros. 1995.90 p. Dissertação (Mestrado em Letras), Universidade Federal do Rio Grande do Sul (UFRGS), Porto Alegre, 1995. 